GEODESY AND CARTOGRAPHY

ISSN 2029-6991 print / ISSN 2029-7009 online

UDK 528.721.221.6

\title{
SCANNING AERIAL PHOTOS USING A NON-PROFESSIONAL SCANNER
}

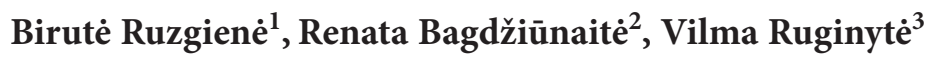 \\ ${ }^{1,2}$ Department of Geodesy and Cadastre, Vilnius Gediminas Technical University, \\ Sauletekio al. 11, LT-10223 Vilnius, Lithuania \\ ${ }^{1}$ Department of Geodesy, Klaipeda State College, Bijünu g. 10, LT-91223 Klaipéda, Lithuania \\ ${ }^{3}$ Department of Geodesy and Land Management, Zemaitija College, L. Ivinskio g. 5, \\ LT-90311 Rietavas, Lithuania \\ E-mails: ${ }^{1}$ birute.ruzgiene@vgtu.lt (corresponding author); ${ }^{2}$ renata.bagdziunaite@vgtu.lt; ${ }^{3}$ v.ruginyte@zemko.lt
}

Received 03 July 2012; 21 September 2012

\begin{abstract}
For scanning analog aerial photographs, digital photogrammetry requires specific and expensive photogrammetric scanners. However, we only have a simple A4 format scanner useful for solving some special photogrammetric tasks applied for analyzing the possibilities of scanning photographic material. The paper investigates the peculiarities of scanning analog aerial photos using the scanner processing pictures smaller than an A4 format. The achieved results are compared with digital data obtained using a professional photogrammetric scanner. Experimental photogrammetric measurements have showed that the results of aerial photographs scanned by a nonprofessional scanner satisfy accuracy requirements for topographic mapping at a scale of 1:5000.
\end{abstract}

Keywords: analog aerial photograph, A4 format scanner, scanning photos, digital photogrammetry, accuracy.

\section{Introduction}

The results of processing photogrammetric data are used for multi-purpose mapping applications, creating geo information databases, etc. (Wolf, Dewitt 2000). Furthermore, techniques for digital photogrammetry can be applied for obtaining low-accuracy data from aerial photographs, for example, analyzing archival photographic material (Suzhedelite-Visotskene et al. 2005).

Digital photogrammetry processes only digital images that can be received when photography is executed using digital cameras or imagery available after scanning the Earth surface from satellites. If aerial photographs are recorded employing standard (analog) mapping cameras, such production must be scanned and converted to a raster/digital format using special electronic equipment - scanners before using them for processing digital images. Scanning analog photographs, particularly archival photographic material, still remains a relevant issue.

Decisions on the scanning process can be defined by the geometric accuracy of the scanned photographs, the amount of information and processing speed. Professional photogrammetric scanners are usually used for digitizing analog aerial photographs. These scanners can produce analog photographic material (negatives or positives) in a digital format fulfilling such basic requirements as capacity for scanning the photographs of an appropriate format (e.g., $23 \times 23 \mathrm{~cm}$ dimensions), available transparency unit and high geometric and radiometric reso- lution. Different types of professional photogrammetric scanners can scan under different maximal scanning resolution, for example, DSW300 LH Systems - $4 \mathrm{~mm}$; SCAI, Zeiss - $7 \mathrm{~mm}$; XL-10ISM - $10 \mathrm{~mm}$; PhotoScan, Z/I - 7 mm (Kraus 2000). Photogrammetric professional scanners are expensive, and therefore not many companies or consumers have a possibility of purchasing them.

A number of scanner types found on the market differ in construction, resolution, format size and price. For low accuracy photogrammetric mapping, aerial photographs can be scanned using flatbed scanners the geometrical scanning accuracy of which makes about $0.05 \mathrm{~mm}$. The main advantage of such scanners is that the price is suitable for each user.

In case there is no possibility of purchasing a professional photogrammetric scanner or using the one that can digitize A3 format material, research into the employment of a widespread scanner of a small format for digitizing photographs can be an option. The goal of investigations is to analyze the possibilities of applying a flatbed scanner able to scan material not larger than A4 size and analog aerial photographs. Digital data obtained from aerial photographs scanned using the A4 format scanner are compared with information on using a professional photogrammetric scanner. In order to evaluate the accuracy of scanning results, the experimental photogrammetric processing of aerial photographs has been conducted. 


\section{Principles of Scanning Aerial Photographs}

The selection of an appropriate scanning interval, i.e. the size of an element (pixel) of a digital picture is an important point in scanning analog aerial photographs. Scanning interval (scan/pixel resolution) $D d$ is specified by the number of dots per inch (dpi) or by micrometers (mm) (Scanning... 2012). Pixel resolution (in terrain units) $D D$ is calculated as

$$
\Delta D(m)=\frac{0,0254 \times \text { photo scale }}{\Delta d(d p i)} .
$$

Typically, photographs are scanned as digital images at pixel resolutions may range from approximately $250 \mu \mathrm{m}$ (100 dots per inch (dpi)) to $10 \mu \mathrm{m}$ (2500 dpi). However, scanning aerial photographs under resolution from 300 to $600 \mathrm{dpi}$ is usually recommended.

The amount of information contained in the digital image depends on the pixel size. Data volume/size (the number of bytes per photograph) determines capacity for disk storage and is related to the speed of image processing. The smaller is the image element, the greater is the image size. Data volume (in $\mathrm{Mb}$ ) increases sharply as scanning resolutions are reduced below $25 \mu \mathrm{m}$ (see Fig. 1) (Welch, Jordan 1996).

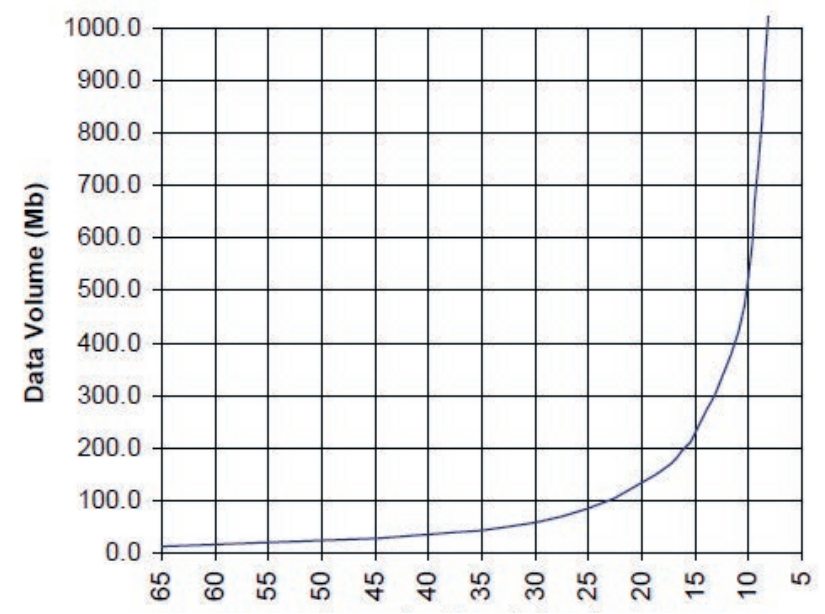

Fig. 1. Relation between data size and scanning resolutions

Scanning resolutions from $84.7 \mu \mathrm{m}$ (300 dpi) to $21.2 \mu \mathrm{m}$ (1200 dpi) will yield ground pixel dimensions between 0.106 and $0.423 \mathrm{~m}$ for the photos at a scale of $1: 5000$ and between 0.212 and $0.847 \mathrm{~m}$ at a scale of 1:10 000. These dimensions correspond with many mapping requirements. In this case, data volumes will approximately make from 8 to 128 Mbytes of computer memory per photo (for a gray scale -8 bit aerial photos).

Selecting scanning resolution at the value necessary for mapping task, consideration for the inherent resolution of original photos may be appropriate, which shows the relation between photo resolution expressed in line pairs per millimetre $(\mathrm{lp} / \mathrm{mm})$ and information content.

As a rule, at least 2-4 pixels are required to represent a feature in an image. Theoretical considerations also show that approximately 2 pixels are required to represent a line pair at the resolution limit of the photograph. Since most photographs recorded by photogram- metric cameras on mapping films have resolutions (on negative) between 20 and $40 \mathrm{lp} / \mathrm{mm}$ for low contrast objects and about 15 to $30 \mathrm{lp} / \mathrm{mm}$ on film transparencies, a scanning interval from $1 / 30 \mathrm{~mm}(33 \mu \mathrm{m})$ to $1 / 60 \mathrm{~mm}$ $(17 \mu \mathrm{m})$ corresponds to original photo resolution when converting analog photos to the digital ones.

A greater pixel size causes the loss of more information, and therefore the results of photogrammetric measurements yield incorrect results. Geometrical scan resolution should be optimal - as high as necessary and as low as possible. An appropriate strategy is setting scanning resolution to the optimal pixel size necessary to identify the smallest features to be extracted and mapped.

An interval of scanning analog aerial photographs is selected depending on accuracy requirements for digital mapping. The accuracy of absolute orientation to scanned aerial images is defined by $1 / 2$ of the pixel size in terrain units. For example, if analog aerial photographs at a scale of 1:6000 are scanned under $50 \mathrm{~mm}$ resolution, the pixel size of the object area is $30 \mathrm{~cm}$. Thus, the accuracy of exterior orientation can reach $25 \mathrm{~mm}$ (15 cm in terrain units), which meets accuracy requirements for the maps of scales between 1:1000 and 1: 2000 .

Maximum attainable accuracy in elevations $(0.1 \%$ o of flaying height) also depends on scan resolution.

The aerial photos of $23 \times 23 \mathrm{~cm}$ exceed an A4 format. Thus, for scanning aerial photographs, an A3 format is necessary, because fiducial marks have to be clearly visible performing inner orientation. Preparation works on scanning photos are executed in the following way: the scanner with no photographs is switched on placing a plate so that the flight direction (e.g., east-west) of the aircraft is parallel to the CCD array (Fig. 2) (Linder 2009).

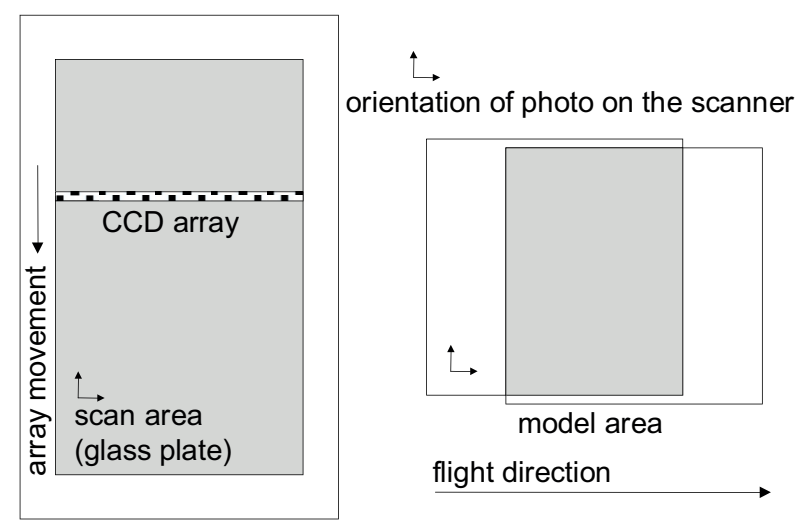

Fig. 2. Orientation of aerial photographs on the flatbed scanner

In case of a simple flatbed scanner able to scan A4 format material at the maximum, scanning analog aerial photos takes place as follows: first, the maximum possible left part of the photos is scanned, including the margin; then, aerial photographs are shifted to the left and the right part of aerial photographs is scanned, including the margin. Also, on the left and right margin of scanned aerial photographs, fiducial marks must be clearly visible. However, black image borders and the side of the 
information bar should be ignored. Both parts of scanned photographic images will have an overlap of about $80 \%$.

Store the scanned parts in suitable image formats such as BMP, JPG and TIFF. The scanned parts of analogical aerial photographs have to be combined using techniques for correlating photographic images.

Digital data received after scanning analog aerial photographs are processed using digital photogrammetric systems.

\section{Experimental Investigations}

Aerial photographs (stereo pair) at a scale of 1:6000 included the northern part of Vilnius city, from one strip were used for experimental study. The positives of aerial photographs were scanned applying professional photogrammetric scanner Vexell Ultra Scan and non- professional scanner Microtec ScanMaker8700 employing the format smaller than A3.

When using the ScanMaker8700, the scanning interval of 500 dpi has been selected. Aerial photographs have been scanned so that the left and right margins of each aerial photograph are clearly visible. An overlap of scanned aerial photographs is about $85 \%$ (Fig. 3 ).

The scanned parts of the image have been matched together using digital photogrammetric system LISA PHOTO (Linder 2009). The program carries out an image matching algorithm based on information about the points in the overlapped area. When applying image pyramids, homologous points are searched and adjusted using affine transformation technique. The parameters of transformation are used for joining two image parts.
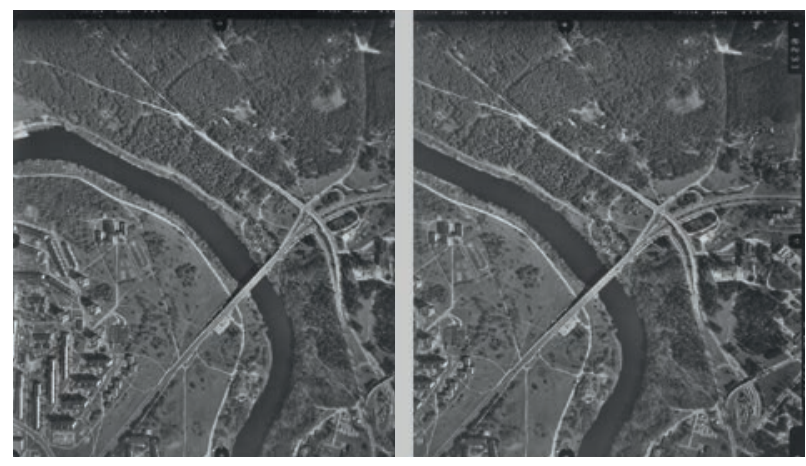

Fig. 3. Scanned aerial photograph: the left and right part of the image

The workflow of experimental study on the analysis of the results of scanning analog aerial photographs is shown in Fig. 4.

When using scanned images, processing and photogrammetric measurements have been done applying photogrammetric digital systems LISA PHOTO and DDPS (Donnay, Kaczynski 2005) in respect to evaluate the accuracy of the images.

The results indicating the accuracy of the inner orientation (with LISA PHOTO) of the left scanned (merged) photographic image are showed in Fig. 5. The maximal residual of coordinate transformation is $0.26 \mathrm{~mm}$ and a standard deviation makes $0.19 \mathrm{~mm}$. Such results of inner orientation do not meet the required accuracy of $0.007 \mathrm{~mm}$ (Kraus 2000) for measuring the accuracy of fiducial marks.

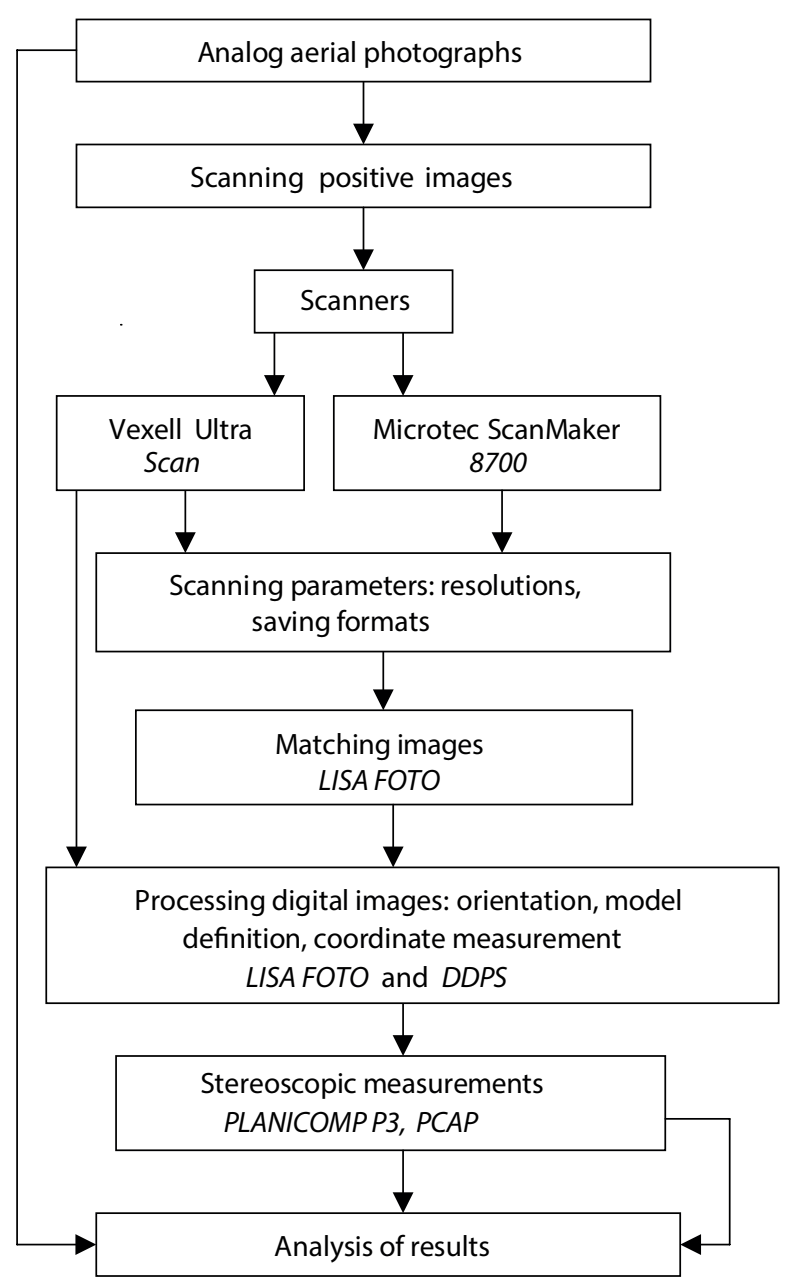

Fig. 4. The workflow of experimental study

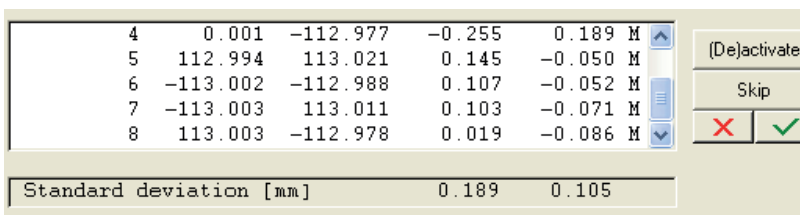

Fig. 5. A fragment of results taken from the inner orientation of the photographic image

The exterior (absolute) orientation of photographic images has been based on 11 reference points the rectangular coordinates of which are defined by an aerial triangulation approach (Ruzgienè, Žalnierukas 1998). The maximal residual error of absolute orientation (with LISA PHOTO) of the left photographic image is $0.24 \mathrm{~mm}$, and a standard deviation is $0.12 \mathrm{~mm}$ (in the system of image coordinates) (Fig. 6).

\begin{tabular}{|c|c|c|c|c|c|c|}
\hline $\begin{array}{l}3226 \\
3227\end{array}$ & $\begin{array}{r}10.635 \\
0.195\end{array}$ & $\begin{array}{l}-61.898 \\
-57.681\end{array}$ & $\begin{array}{r}0.233 \\
-0.027\end{array}$ & $\begin{array}{r}0.033 \mathrm{M} \wedge \\
-0.164 \mathrm{M}\end{array}$ & \multicolumn{2}{|c|}{ (De)activat } \\
\hline 3230 & -90.653 & -97.065 & -0.104 & $0.213 \mathrm{M}$ & \multicolumn{2}{|c|}{ Skip } \\
\hline 3307 & 4.800 & 3.242 & 0.241 & $0.055 \mathrm{M}$ & & \\
\hline 3308 & -91.401 & -17.426 & -0.065 & $0.163 \mathrm{M} \mathrm{V}$ & $\mathrm{X}$ & $V$ \\
\hline ard & on & & 0.123 & 0.120 & & \\
\hline
\end{tabular}

Fig. 6. A fragment of results taken from exterior image orientation 
The results of the accuracy of the inner and exterior orientation of the right photographic image are similar.

The orientation of images has been carried out using digital photogrammetric program DDPS. The accuracy results of orientation are similar to those using LISA PHOTO.

After creating the model of clearly visible points/ objects (about 50 points), the stereoscopic measurements of coordinates using LISA PHOTO software and semiautomatic measurements employing DDPS have been done. For a comparison of measurement results, the coordinates of the same points have been determined using photographic images scanned by professional photogrammetric scanner Vexell Ultra Scan under a resolution of $14 \mathrm{~mm}$ (Ruzgienè 2007). In addition, the coordinates of the points have been stereoscopically measured in positives applying analytical photogrammetric instrument PLANICOMP P3 and using software PCAP for stereo pair orientation (Ruzgiené, Aleknienè 2007).

For evaluating the results of photogrammetric measurements, deviations from the coordinates of the points have been calculated in respect of the coordinates determined by the analytical photogrammetry method.

In general, the determined coordinates of points using photogrammetric measurements and techniques mentioned above have been analyzed. Experimental investigations indicate a root mean square error of $0.50 \mathrm{~m}$ and a standard deviation of $0.30 \mathrm{~m}$ in horizontal coordinates when comparing measurement results obtained using digital data from non professional scanner A4 format and from the professional scanner scanned aerial photographs.

\section{Conclusions}

Scanning analog aerial photographs of format $23 \times 23 \mathrm{~cm}$ using a non-professional scanner allows examining the material of the format not large than A4; however, the problem of connecting two parts of the scanned data occurs. The correlation results of photographic images have showed that the significant distortion of a photographic image appears on the edges of the photos. Such effect influences the results of internal orientation (see Fig. 5).

The scanning process takes about 2 times longer than scanning employing the other type of a scanner (professional photogrammetric scanner and A4 format scanner).

When analogue aerial photographs (at a scale of 1:6000) are scanned under a resolution of at least $500 \mathrm{dpi}$ $(50.8 \mu \mathrm{m})$, appropriate accuracy requirements for the results of photogrammetric measurements are not reached.

The analysis of scanning results, a comparison of digital data on scanning applying professional and nonprofessional scanners and photogrammetric experimental measurements indicate that the results of aerial pho- tographs scanned by a non-professional scanner satisfy accuracy requirements for topographic maps at a scale of 1:5000.

\section{References}

Donnay, J. P.; Kaczynski, R. 2005. Didactic and Digital Photogrammetric Software. User's Guide. Department of Geomatics, University of Liege, Belgium, Institute of Geodesy and Cartography, Department of Photogrammetry, Warszawa, Poland. $71 \mathrm{p}$.

Kraus, K. 2000. Photogrammetry. Vol. 1. Fundamentals and Standard Processes. Köln, Dümmler. 396 p.

Linder, W. 2009. Digital Photogrammetry. A Practical Course. Springer-Verlag, Berlin, Heidelberg. 226 p.

Ruzgienè, B.; Aleknienè, E. 2007. Analytical and digital photogrammetric geodata production systems (a comparison test), Geodezija ir kartografija [Geodesy and Cartography] 33(2): 50-54.

Ruzgienè, B.; Žalnierukas, A. 1998. Aerotrianguliacija naudojant kinematinio GPS metodo rezultatus, Geodezija ir kartografija [Geodesy and Cartography] 24(1): 16-25.

Ruzgienè, B. 2007. Comparison between digital photogrammetric systems, Geodezija ir kartografija [Geodesy and Cartography] 33(3): 75-79.

Scanning analog photographs [cited 2 July 2012]. Available from Internet: http://academic.emporia.edu/aberjame/airphoto/scan.htm

Suzhedelite-Visotskene, Iu.; Zigmantene, E.; Zhalnerukas, A. 2005. Ispolzovanie aerofotosnimkov dlia tselej kadastra, $\mathrm{Va}$ gos: Mokslo darbai 67(20): 97-101. Kaunas.

Welch, R.; Jordan, T. 1996. Using Scanned Aerial Photographs [cited 2 July 2012].- Available from Internet: http://www. crms.uga.edu/pubs/raster_images_in_gis.pdf

Wolf, P. R.; Dewitt, B. A. 2000. Elements of Photogrammetry: with Application in GIS. 3rd edition. McGraw-Hill. 608 p.

Birutè RUZGIENĖ. Assoc. Prof., Dr at the Department of Geodesy and Cadastre, Vilnius Gediminas Technical University, Saulètekio al. 11, LT-10223 Vilnius, Lithuania. Ph +370 5 2744703, Fax +370 5 2744705, e-mail: birute.ruzgiene@vgtu.lt. Research interests: digital photogrammetric mapping, image interpretation, feature extraction from remote sensing data.

Renata BAGDŽIŪNAITĖ. Assoc. Prof., Dr at the Department of Geodesy and Cadastre, Vilnius Gediminas Technical University, Saulètekio al. 11, LT-10223 Vilnius, Lithuania. $\mathrm{Ph}+370$ 5 2744703, Fax +370 5 2744705, e-mail: renata.bagdziunaite@ vgtu.lt. Research interests: cartography, GIS modelling.

Vilma RUGINYTE். Lecturer at the Department of Geodesy and Land Management, Zemaitija College, L. Ivinskio g. 5, LT-90311 Rietavas, Lithuania. $\mathrm{Ph}+370682$ 51859, Fax +370 448 69584, e-mail: v.ruginyte@zemko.lt. Research interests: digital photogrammetry, modelling spatial data. 